Working Paper/Document de travail

2007-29

\title{
Exchange Rate Regimes, Globalisation, and the Cost of Capital in Emerging Markets
}

by Antonio Diez de los Rios 
Bank of Canada Working Paper 2007-29

April 2007

\title{
Exchange Rate Regimes, Globalisation, and the Cost of Capital in Emerging Markets
}

\author{
by \\ Antonio Diez de los Rios \\ Financial Markets Department \\ Bank of Canada \\ Ottawa, Ontario, Canada K1A 0G9 \\ adiez@bankofcanada.ca
}

Bank of Canada working papers are theoretical or empirical works-in-progress on subjects in economics and finance. The views expressed in this paper are those of the author.

No responsibility for them should be attributed to the Bank of Canada. 


\section{Acknowledgements}

This paper is a thoroughly revised and updated version of Chapter II of my Ph.D. dissertation. I am very grateful to my advisor Enrique Sentana for his guidance and comments. I would also like to thank Manuel Arellano, José Manuel Campa, Scott Hendry, and Simón Sosvilla for their comments on earlier versions of this paper. Thanks are also due to Elena Nemykina for her useful help in collecting the data used in this paper. All remaining errors are mine. 


\begin{abstract}
This paper presents a multifactor asset pricing model for currency, bond, and stock returns for ten emerging markets to investigate the effect of the exchange rate regime on the cost of capital and the integration of emerging financial markets. Since there is evidence that a fixed exchange rate regime reduces the currency risk premia demanded by foreign investors, the tentative conclusion is that a fixed exchange rate regime system can help reduce the cost of capital in emerging markets.
\end{abstract}

JEL classification: F30, F33, G15

Bank classification: Exchange rate regimes; Development economics

\title{
Résumé
}

À l'aide d'un modèle multifactoriel d'évaluation des actifs mettant à contribution les données relatives aux rendements observés sur les marchés de devises, d'obligations et d'actions de dix économies émergentes, l'auteur analyse l'incidence du choix de régime de change sur le coût du capital et l'intégration des marchés financiers des économies émergentes. D'après les résultats qu'il obtient, l'adoption d'un régime de changes fixes entraîne une baisse de la prime de risque de change exigée par les investisseurs étrangers. La conclusion que l'auteur en tire provisoirement est qu'un tel régime peut aider à réduire le coût du capital dans les économies émergentes.

Classification JEL : F30, F33, G15

Classification de la Banque : Régimes de taux de change; Économie du développement 


\section{Introduction}

In an attempt to reduce the uncertainty that firms and investors face when making investment decisions, different countries have pursued policies oriented to the stabilisation of their exchange rates. One clear and extreme example of these attempts took place in January 1, 1999, when the conversion rates versus the "Euro" of eleven European countries were irrevocably fixed in order to start the third stage of the European Monetary Union (EMU). It was claimed at that moment in time that the single currency would provide a new economic framework where firms did not need to compensate investors for the exchange rate risk. This reduction in the cost of capital would, therefore, open new investment opportunities, stimulate corporate investment and, ultimately, foster investment and growth.

However, as claimed in Sentana (2002), the arguments in favour of a fixed exchange rate regime suffer from several criticisms. First, since firms might be able to hedge their exchange rate exposure it can be the case that they are not affected by any idiosyncratic movement in exchange rates. Second, it can be the case that these idiosyncratic exchange rate risks are not priced in a world with complete market integration. And finally, a fixed exchange rate system will increase interest rate volatility since monetary authorities have to defend their respective parities; and, as long as interest rate volatility might be priced in emerging markets, it is conceptually possible that a fixed exchange rate regime can increase the cost of capital. Nevertheless, Sentana (2002) has found that, despite these three points, the European Monetary System (EMS) has lowered the cost of capital of European firms, "although the effect is small".

At the same time that the "European Experience" went on, policies of exchange rate stabilisation, jointly with those attempting the liberalization of financial markets, were blamed for the increase in the frequency and recurrence of the financial upheavals in emerging markets. This prompts a debate on the appropriate choice of an exchange rate regime for a developing country (Levy-Yeyati and Sturzenegger, 2003; and Reinhart and Rogoff, 2004). For one, emerging markets present several characteristics that can accentuate the benefits as well as the previously mentioned negative aspects of a fixed exchange rate regime. External financing is relatively more important in emerging countries. For example, the U.S. holdings of Mexican equities at the end of the year 2001 were approximately $20 \%$ of the domestic market capitalization (Department of the U. S. Treasury, 2003). Therefore, a reduction of the exchange rate variability could provide a stable framework that stim- 
ulates foreign investment. On the other hand, Calvo and Reinhart (2002) argue that the lack of credibility of the exchange rate stabilization policies implemented by the emerging countries' governments has caused excess volatility in interest rates. This makes the tradeoff between exchange and interest rate volatility to be especially relevant for the study considered here.

This paper studies the impact of the choice of an exchange rate regime on the cost of capital in emerging markets. To do so, I rely on the framework of the dynamic version of the arbitrage pricing theory (APT) developed in King, Sentana and Wadhwani (1994) and extended in Sentana (2002) to study the impact of EMS on the cost of capital of European firms.

In particular, I use weekly data on currency, bond and stock returns for ten emerging markets over the period from mid 1997 to mid 2006 to estimate a multivariate factor model with time-varying volatility in the underlying factors. However, I include two modifications to the analysis done in Sentana (2002). First, I do not restrict the structure of the common factor to be triangular because general equilibrium models usually predict that all common factors affect all asset classes. ${ }^{1}$ Second, I follow Jorion (1988), Vlaar and Palm (1993) and Das (2002) and combine a GARCH specification with the presence of Gaussian jumps. This allows the model to capture the several episodes of financial distress that occur in the sample (for example, the East Asian crises of 1997, the Russian collapse of 1998, the devaluation of the Brazilian Real in 1999, and the abandonment of the Argentinean currency board in 2002).

In addition, it is difficult to disentangle the study of the impact of the exchange rate regime on the cost of capital and the study of the hypothesis of financial market integration. Ultimately, the impact depends on whether country-specific risks are priced. The assetpricing model used in this paper implicitly assumes that emerging markets are integrated. Thus, testing the cross-equation restrictions of the basic model allows the paper to answer if country-specific risks are priced. I also follow Stulz (1999) to gauge the potential gains from stock market globalisation by comparing the risk premia that would prevail in a world of full integration and full segmentation.

The paper is organized as follows. Section 2 presents the benchmark model and the estimation procedure. Section 3 reports the empirical results. The impact of an exchange

\footnotetext{
${ }^{1}$ See Pavlova and Rigobon (2006) for a general equilibrium model with exchange rates, bond and stock prices.
} 
regime on the cost of capital is analysed in section 4. Section 5 discusses whether emerging markets are financially integrated. Finally, section 6 concludes.

\section{Benchmark model}

This section borrows from Sentana (2002), where further details can be found. However, I will highlight any significant change with respect to his work.

\subsection{Asset pricing model}

The analysis is based in a world with a large number of countries $j=1, \ldots, N$, and assumes that for each country there are three representative assets available: a one-period local currency $(c)$ deposit with safe gross return $R_{c j t}^{j}$; a long-term default-free bond portfolio (b), which has a random gross holding return over period $t$ in local currency given by $R_{b j t}^{j}$; and a stock portfolio $(s)$, with a random gross holding return in local currency given by $R_{s j t}^{j}$. Let $S_{j t}^{\$}$ be the spot exchange rate for country $j$ at the end of period $t$ in terms of the numeraire currency (US\$ in this case), and let $R_{c \$ t}^{\$}$ be the gross return on the safe asset for US during period $t$ in US\$. In this context, the excess returns of these three representative assets for each country in terms of the numeraire currency will be given by:

$$
\begin{aligned}
r_{c j t}^{\$} & =\log R_{c j t}^{\$}-\log R_{c \$ t}^{\$}=\log S_{j t}^{\$}-\log S_{j t-1}^{\$}+\log R_{c j t}^{j}-\log R_{c \$ t}^{\$}, \\
r_{b j t}^{\$} & =\log R_{b j t}^{\$}-\log R_{c \$ t}^{\$}, \\
r_{s j t}^{\$} & =\log R_{s j t}^{\$}-\log R_{c \$ t}^{\$},
\end{aligned}
$$

where $r_{c j t}^{\$}, r_{b j t}^{\$}$ and $r_{s j t}^{\$}$ are the (continuously compounded) excess returns for currency, bonds and stocks in US\$, respectively. In particular, the notation structure is as follows: for an excess return $r_{a j t}^{\$}$, the first subscript $a=c, b, s$ is related to the asset, the second one $j$ is related to the country, and the third one $t$ is related to the period of time. Superscript indicates the currency in which the asset is denominated, and, for clarity of exposition, it will only appear when the excess return refers to local currency. Thus, the lack of a superscript reflects excess returns denominated in US\$. In addition, let $\mu_{a j t}$ and $\eta_{a j t}$ be the risk premia term and the unanticipated (as of $t-1$ ) component of the excess return $r_{a j t}=\mu_{a j t}+\eta_{a j t}$. The subscript and the superscript structure for $\mu_{a j t}$ and $\eta_{a j t}$ is the same used for excess returns. 
Furthermore, assume the existence of three "global" latent factors affecting the returns on the three assets considered. At this moment let the common factors be named as: the exchange rate factor $\left(f_{e t}\right)$, the interest rate factor $\left(f_{i t}\right)$, and the residual market factor $\left(f_{m t}\right)$. Since asset returns are also affected by the country-specific factors, I postulate the existence of three idiosyncratic factors per country in addition to the above mentioned common (global) factors. These country specific factors are, again, related to the exchange rate $\left(v_{j e t}\right)$, the interest rate $\left(v_{j i t}\right)$, and the residual market risks $\left(v_{j m t}\right)$. On this basis, I assume the following factor structure for the unanticipated component of returns:

$$
\begin{aligned}
& \eta_{c j t}=\beta_{c j e} f_{e t}+\beta_{c j i} f_{i t}+\beta_{c j m} f_{m t}+v_{j e t}, \\
& \eta_{b j t}=\beta_{b j e} f_{e t}+\beta_{b j i} f_{i t}+\beta_{b j m} f_{m t}+\delta_{b j e} v_{j e t}+v_{j i t}, \\
& \eta_{s j t}=\underbrace{\beta_{s j e} f_{e t}+\beta_{s j i} f_{i t}+\beta_{s j m} f_{m t}}_{\text {Systematic risk }}+\underbrace{\delta_{s j e} v_{j e t}+\delta_{s j i} v_{j i t}+v_{j m t}}_{\text {Country-specific risk }},
\end{aligned}
$$

or in matrix notation $\boldsymbol{\eta}_{j t}=\mathbf{B}_{j} \mathbf{f}_{t}+\boldsymbol{\Delta}_{j} \mathbf{v}_{j t}$, where $\mathbf{f}_{t}=\left(f_{e t}, f_{i t} f_{m t}\right)^{\prime}, \mathbf{v}_{j t}=\left(v_{j e t}, v_{j i t}, v_{j m t}\right)^{\prime}$, and $\beta$ 's and $\delta$ 's are the (time-invariant) factor loadings which measure the sensitivity of the assets to the different common and idiosyncratic factors, respectively. ${ }^{2}$

Two comments are in order here. First, the triangular structure imposed on the countryspecific factors is arbitrary but not restrictive. It is arbitrary because, taking the common factors as given, the factor loadings of the idiosyncratic risks cannot be identified up to an orthogonal rotation. On the other hand, it is not restrictive because the assumption $\left|\boldsymbol{\Delta}_{j}\right|=1$ implies that the unconditional idiosyncratic variance-covariance matrix remains totally unrestricted within a country. ${ }^{3}$ Moreover, this orthogonalisation allows one to provide sensible names to each of the idiosyncratic factors and, therefore, to ease the interpretation of the results. In particular: "exchange rate" is the factor that affects the idiosyncratic component of a deposit in local currency; "interest rate" is the factor that affects the idiosyncratic component of the bond but not the deposit return; while "residual market" only affects the idiosyncratic component of the stock return. Second, Sentana (2002) assumes that the deposit returns are only affected by the common exchange rate factor, and that bond returns are only affected by the exchange and the interest rate factor

\footnotetext{
${ }^{2}$ The first subscript of $\beta_{a j k}, \delta_{a j k}, a=c, b, s$ is related to the asset, the second one $j$ is related to the country and finally the third one $k=e, i, m$ is related to the factor. For instance, $\beta_{a j k}$ reflects the sensitivity of country $j$ 's return in US $\$$ on asset $a$ to factor $k$. Again, for clarity of exposition, those superscripts that refer to US\$ denominated assets are omitted.

${ }^{3}$ See Sentana and Fiorentini (2001), Sentana (2002), and Rigobon (2003) for further details on the identification issue.
} 
(i.e. $\beta_{c j i}=\beta_{c j m}=\beta_{b j m}=0$ ). But given that it is difficult to justify from an empirical and theoretical point of view that the common (global) factor structure is triangular, I relax this assumption to provide more flexibility in the structure of covariances of the returns.

Further assumptions are as follows: First, to guarantee that the unanticipated component (as of $t-1$ ) of the returns $\eta$ 's are in fact innovations, the common and specific factors are unpredictable on the basis of past information. Second, the common factors are orthogonal to each other, but they have time-varying conditional variances $\lambda_{e t}, \lambda_{i t}, \lambda_{m t}$. As a consequence, the implied risk premia will be time-varying. Third, the idiosyncratic factors, which by definition are orthogonal to $\mathbf{f}_{t}$, are orthogonal to one another for a given country $j$, and again, they have time-varying conditional variances $\omega_{j e t}, \omega_{j i t}, \omega_{j m t}$. Finally, the idiosyncratic factors can be correlated across countries, but only mildly to guarantee that full diversification applies. That is, the conditional covariance matrix has the Chamberlain and Rothschild (1983) approximate zero-factor structure.

Finally, one can appeal to a no-arbitrage argument to assume that there is a stochastic discount factor (also known as pricing kernel) that prices the available assets by discounting their uncertain payoffs across different states of the world. In particular, assuming a linear model in the common factors for the pricing kernel, the risk premia will have the following beta representation: ${ }^{4}$

$$
\begin{aligned}
& \mu_{c j t}^{0}=\beta_{c j e} \tau_{e} \lambda_{e t}+\beta_{c j i} \tau_{i} \lambda_{i t}+\beta_{c j m} \tau_{m} \lambda_{m t}, \\
& \mu_{b j t}^{0}=\beta_{b j e} \tau_{e} \lambda_{e t}+\beta_{b j i} \tau_{i} \lambda_{i t}+\beta_{b j m} \tau_{m} \lambda_{m t}, \\
& \mu_{s j t}^{0}=\beta_{s j e} \tau_{e} \lambda_{e t}+\beta_{s j i} \tau_{i} \lambda_{i t}+\beta_{s j m} \tau_{m} \lambda_{m t},
\end{aligned}
$$

where, $\tau_{k}(k=e, i, m)$ corresponds to the price of risk for factor $k$, that is, the amount of expected return that agents demand in order to accept another unit of volatility. Note that under this benchmark any country specific risk should not be priced, because it can be diversified away.

\subsection{Alternative hypotheses}

To investigate whether the choice of an exchange rate regime is able to reduce the cost of capital in emerging markets I follow Sentana (2002) to encompass the asset-pricing model

\footnotetext{
${ }^{4}$ See Cochrane (2001) and Sentana (2002).
} 
in a more general set-up:

$$
\begin{aligned}
& \mu_{c j t}=\mu_{c j t}^{0}+\theta_{c j e} \lambda_{e t}+\theta_{c j i} \lambda_{i t}+\theta_{c j m} \lambda_{m t}+\rho_{c j e} \omega_{j e t}, \\
& \mu_{b j t}=\mu_{b j t}^{0}+\theta_{b j e} \lambda_{e t}+\theta_{b j i} \lambda_{i t}+\theta_{b j m} \lambda_{m t}+\rho_{b j e} \omega_{j e t}+\rho_{b j i} \omega_{j i t}, \\
& \mu_{s j t}=\mu_{s j t}^{0}+\theta_{s j e} \lambda_{e t}+\theta_{s j i} \lambda_{i t}+\theta_{s j m} \lambda_{m t}+\rho_{s j e} \omega_{j e t}+\rho_{s j i} \omega_{j i t}+\rho_{s j m} \omega_{j m t},
\end{aligned}
$$

where $\mu_{c j t}^{0}, \mu_{b j t}^{0}$ and $\mu_{s j t}^{0}$ are defined in equation (2).

This system of equations enables one to test several of the hypotheses of interest. First, one can test whether the exchange rate idiosyncratic risk is priced in bond and stock returns $\left(\rho_{\text {bje }}=\rho_{\text {sje }}=0\right)$. If this risk is not priced, the choice of an exchange rate regime will have no impact on the currency component of the cost of capital. Second, if the interest rate idiosyncratic risk is priced in bond and stock returns $\left(\rho_{b j i} \neq 0\right.$ or $\left.\rho_{s j i} \neq 0\right)$ then the choice of an exchange rate regime can affect the cost of capital when there is an increase in the interest rate volatility caused by the defense of a fixed exchange rate regime. Third, it is also possible that other sources of idiosyncratic risk are priced in stocks $\left(\rho_{s j m} \neq 0\right)$ which would reveal that emerging markets are not fully integrated. Finally, I investigate whether the prices of risk are common across countries $\left(\theta_{a j k}=0 \forall a=c, b, s \forall k=e, i, m\right)$.

\section{$2.3 \quad$ Estimation method}

Given that $r_{a j t}=\mu_{a j t}+\eta_{a j t}$ by construction, I combine the system of equations (1) and (2) to write the model in compact form as:

$$
\begin{aligned}
& r_{c j t}=\beta_{c j e} f_{e t}^{R}+\beta_{c j i} f_{i t}^{R}+\beta_{c j m} f_{m t}^{R}+v_{j e t}, \\
& r_{b j t}=\beta_{b j e} f_{e t}^{R}+\beta_{b j i} f_{i t}^{R}+\beta_{b j m} f_{m t}^{R}+\delta_{b j e} v_{j e t}+v_{j i t}, \\
& r_{s j t}=\beta_{s j e} f_{e t}^{R}+\beta_{s j i} f_{i t}^{R}+\beta_{s j m} f_{m t}^{R}+\delta_{s j e} v_{j e t}+\delta_{s j i} v_{j i t}+v_{j m t},
\end{aligned}
$$

or in matrix notation $\mathbf{r}_{j t}=\mathbf{B}_{j} \mathbf{f}_{t}^{R}+\boldsymbol{\Delta}_{j} \mathbf{v}_{j t}$. Here $f_{k t}^{R}=\tau_{k} \lambda_{k t}+f_{k t}=\pi_{k t}+f_{k t}(k=e, i, m)$ can be interpreted as excess returns of three diversified portfolios, $\mathbf{f}_{t}^{R}=\left(f_{\text {et }}^{R}, f_{i t}^{R}, f_{m t}^{R}\right)^{\prime}$, that mimic the proposed factors. In particular, $\pi_{k t}$ represents the risk premia of the common factor $k$ and $f_{k t}$ is the corresponding unanticipated component (as of $t-1$ ).

Note that if $\mathbf{f}_{t}^{R}$ were observed directly, estimation would be an easy task since one would be able (in the conditional homoscedastic case) to recover $\mathbf{B}_{j}$ and $\boldsymbol{\Delta}_{j}$ by a set of OLS regressions. ${ }^{5}$ In this particular case where $\mathbf{f}_{t}^{R}$ is observed and conditionally homoscedastic,

\footnotetext{
${ }^{5}$ Alternatively, under the assumption of conditional normality, the system given by (4) could be es-
} 
the structure of the problem allows the estimation of $\mathbf{B}_{j}$ and $\boldsymbol{\Delta}_{j}$ by maximum likelihood (ML) simply as follows (see Sentana 2002 and references therein):

(a) $\beta_{c j e}, \beta_{c j i}, \beta_{c j m}$ and $\omega_{j e}$ from the OLS regression of $r_{c j t}$ on $f_{e t}^{R}, f_{i t}^{R}$ and $f_{m t}^{R}$.

(b) $\beta_{b j e}, \beta_{b j i}, \beta_{b j m}, \delta_{b j e}$ and $\omega_{j i}$ from the OLS regression of $r_{b j t}$ on $f_{e t}^{R}, f_{i t}^{R}$ and $f_{m t}^{R}$ with the residual from (a) as an extra regressor.

(c) $\beta_{s j e}, \beta_{s j i}, \beta_{s j m}, \delta_{s j e}, \delta_{s j i}$ and $\omega_{j m}$ from the OLS regression of $r_{s j t}$ on $f_{e t}^{R}, f_{i t}^{R}$ and $f_{m t}^{R}$ with the residuals from (a) and (b) as extra regressors.

However, this is not the case because there is no data available on $\mathbf{f}_{t}^{R}$. Still, I follow Sentana (2002) and construct three fully diversified global portfolios of currency deposits, bonds and stocks which by definition do not contain any idiosyncratic risk. Let the excess returns on these three portfolios be denoted by $\mathbf{r}_{p t}=\left(r_{c p t}, r_{b p t}, r_{s p t}\right)^{\prime}$ and assume that they are related to the common risk factors in the following way:

$$
\begin{aligned}
& r_{c p t}=f_{\text {et }}^{R}, \\
& r_{\text {bpt }}=\beta_{\text {bpe }} f_{\text {et }}^{R}+f_{i t}^{R}, \\
& r_{s p t}=\beta_{\text {spe }} f_{\text {et }}^{R}+\beta_{\text {spi }} f_{i t}^{R}+f_{m t}^{R},
\end{aligned}
$$

or in matrix notation $\mathbf{r}_{p t}=\mathbf{B}_{p} \mathbf{f}_{t}^{R}$, where the scaling of the common factors are set to $\beta_{\text {cpe }}=\beta_{\text {bpi }}=\beta_{\text {spm }}=1 .^{6}$

Now, I can estimate $\mathbf{B}_{p}$, recover the set of mimicking portfolios as $\widehat{\mathbf{f}}_{t}^{R}=\widehat{\mathbf{B}}_{p}^{-1} \mathbf{r}_{p t}$ and run the OLS regressions in (a), (b) and (c) with $\widehat{\mathbf{f}}_{t}^{R}=\left(\widehat{f}_{e t}^{R}, \widehat{f}_{i t}^{R}, \widehat{f}_{m t}^{R}\right)$ instead of $\mathbf{f}_{t}^{R}$. In other words, adding the three portfolios in (5) to the list of $3 N$ assets allows the factorisation of the joint likelihood function of the $3(N+1)$ assets into the marginal component of $\mathbf{r}_{p t}$ and the conditional components corresponding to all the individual countries given the fully

timated for any $N$ countries simultaneously by maximum likelihood (see King, Sentana and Wadhwani, 1994). But as claimed in Sentana (2002): "with three assets per country and a non-diagonal time-varying conditional idiosyncratic covariance matrix, though, this results in a very time-consuming procedure even for moderately large $N "$.

${ }^{6} \mathrm{As}$ in the case of the idiosyncratic factors, the triangular structure imposed on the diversified portfolios is arbitrary but not restrictive. Again, the factor loadings of the three diversified portfolios to the common risks cannot be identified up to an orthogonal rotation and therefore we can always redefine the diversified portfolios and get the same covariance structure. Nevertheless, under a different orthogonalisation it would be difficult to understand these common factors as "exchange rate", "interest rate" and "residual market". Moreover, it is important to note that this specification is not restrictive because, given the assumption $\left|\mathbf{B}_{p}\right|=1$, the unconditional variance-covariance matrix of the global portfolios remains totally unrestricted. 
diversified portfolios. In particular, under conditional homoskedasticity, (5) is a recursive simultaneous equation system whose parameter estimates can be obtained in the following way:

(d) $\pi_{e}$ and $\lambda_{e}$ from the OLS regression of $r_{c p t}$ on a constant.

(e) $\beta_{b p e}, \pi_{i}$ and $\lambda_{i}$ from the OLS regression of $r_{b p t}$ on $r_{c p t}$ and a constant.

(f) $\beta_{s p e}, \beta_{s p i}, \pi_{m}$ and $\lambda_{m}$ from the OLS regression of $r_{s p t}$ on $r_{c p t},\left(r_{b p t}-\widehat{\beta}_{b p e} r_{c p t}\right)$ and a constant, where $\widehat{\beta}_{b p e}$ is the estimation of the parameter $\beta_{b p e}$ obtained in (e).

Therefore, one would estimate the system of the diversified portfolios (5) in a first stage, and then estimate the corresponding system for the individual countries in (4) in a second step. But given that I am using estimates of the diversified portfolios system to compute the regressors of the second stage, the inference will not be valid because it suffers from a "generated regressors problem". This is solved by estimating the joint system and recasting the estimation within the Generalized Method of Moment (GMM) framework using the moment conditions that are implicit in the OLS estimation in (a)-(f). Moreover, a significant advantage of the GMM framework is that estimates of $\pi$ 's, $\beta$ 's and $\delta$ 's remain consistent when factors suffer from serial correlation and/or are affected by conditional heteroscedasticity, provided that the factor representing portfolios and idiosyncratic factors remain contemporaneously uncorrelated.

Similarly, the alternative hypotheses stated in section 2.2 can also be tested within the GMM-regression framework. For example, I can add the conditional variance of $v_{j e t}, \omega_{j e t}$ as an additional regressor in equation (4a) and test whether the estimated coefficient $\rho_{\text {cje }}$ is different from zero. Doing so yields an estimate of $\rho_{c j e}$ which measures the impact of the elimination of idiosyncratic exchange rate volatility.

In practice, the conditional variance is an unobserved variable and, instead, one has to use an estimate $\widehat{\omega}_{\text {jet }}$. Although I could follow Sentana (2002) to estimate volatilities by means of GARCH $(1,1)$ regressions, this model fails in replicating the episodes of financial distress that characterize emerging market returns. Consequently, I follow instead Jorion (1988), Vlaar and Palm (1993) and Das (2002) to combine a GARCH specification with the presence of Gaussian jumps. The estimation of these GARCH-jump models is done by replacing the OLS regressions in (a)-(c) by GARCH-jump regressions, and replacing 
the OLS regressions in (d)-(f) by GARCH-in-mean-jump regressions. ${ }^{7}$ Moreover, if the proposed conditional variance specification were incorrect, the tests would still be consistent albeit less powerful. In addition, the tests will have the correct asymptotic size under the null hypothesis despite the fact that conditional variances are generated regressors. ${ }^{8}$

\section{Results}

\subsection{Data}

The database comprises weekly data for currency, bond and stock returns on a set of ten emerging markets during the period 4 June 1997 - 28 June 2006 (474 observations). It includes four Latin-American countries: Argentina, Brazil, Mexico, and Venezuela; four Asian markets: China, Malaysia, Philippines, and Thailand; and two East European economies: Poland, and Russia. This set of countries has been chosen on a data-availability basis. An appendix with data sources is provided.

I also include data on developed countries to aggregate well-diversified portfolios that contain the non-emerging markets as well. These are Australia, Canada, Japan, the United States and ten European countries (Belgium, Denmark, France, Germany, Italy, Netherlands, Spain, Sweden, Switzerland and the United Kingdom). In particular, these data are used to construct three equally weighted portfolios: a "world" equally weighted portfolio of currency returns, a "world" equally weighted portfolio of bond returns, and a "world" equally weighted portfolio of stock returns as the set of portfolios in system (5).

\subsection{Estimates of the baseline asset pricing model}

I first estimate the baseline model of section 2 by GMM under the null hypothesis of integration of financial markets. In order to obtain estimates of the conditional variances, I then fit a GARCH-in-mean-jump model to the common factors estimated in the first step, and a GARCH-jump model to the estimated idiosyncratic factors.

The parameter estimates of the diversified portfolios subsystem, equation (5), are presented in Table 1. These results indicate that the three diversified portfolios are positively correlated, which is partly explained by the fact that all returns are denominated in US\$. The parameter estimates also confirm the result found in Sentana (2002) that, controlling

\footnotetext{
${ }^{7}$ See the appendix for the specific details of the likelihood function of GARCH-jump models.

${ }^{8}$ See Sentana (2002) for details on these two last issues.
} 
for movements in exchange rates, world bond returns and world stock returns are positively correlated. While the estimated risk premia on the interest rate and residual market are positive, the exchange rate risk premia is negative. However, none of the three risk premia is estimated precisely. The interest rate risk premia is significant, though, but only at the ten percent level. ${ }^{9}$

Table 2 reports the estimates of the factor loadings of currency deposit, bond and stock returns on each one of the factors. In particular, the parameter estimates of the sensitivities of the currency deposit returns to the three common risk factors are presented in the Table $2 \mathrm{a}$. In the first column, I find that the coefficient on the common exchange rate factor, $\beta_{c j e}$, is positive for the ten countries analyzed in this paper and this coefficient is significant ${ }^{10}$ for eight out of the ten countries. Since the common link across all the exchange rates is the numeraire currency, these positive coefficients suggest that currency returns decrease (increase) when the dollar appreciates (depreciates). In the second column, one can see that the currency deposit return of Mexico and Poland are positively correlated with the "world" portfolio of bond returns, while the currency deposits in Malaysia are negatively correlated. For the rest of the countries, $\beta_{c j i}$ is not statistically different from zero. Finally, in the third column, all the countries have a coefficient $\beta_{c j m}$ that is positive. Still, only Argentina, Brazil, Mexico, Philippines, Thailand and Poland present a positive coefficient that is statistically different from zero.

While the sensitivities of currency deposit returns to the risk factors correspond to assets denominated in US\$, the parameter estimates in table $2 \mathrm{~b}$ and $2 \mathrm{c}$ correspond to bond and stock returns denominated in local currency. This way, one can isolate any indirect effect of exchange rates onto asset returns. Moreover, the analysis presented in the previous section is still valid because the asset pricing model considers currency deposit returns and, therefore, the framework presented in section 2.1 can also be used to price bond and stock returns in local currency. Specifically, note that local currency bond and stock excess returns can be expressed as $r_{b j t}^{j}=r_{b j t}-r_{c j t}$ and $r_{s j t}^{j}=r_{s j t}-r_{c j t}$. Making use of these expressions and those in (4) I can write:

$$
\begin{aligned}
r_{b j t}^{j} & =\left(\beta_{b j e}-\beta_{c j e}\right) f_{e t}^{R}+\left(\beta_{b j i}-\beta_{c j i}\right) f_{i t}^{R}+\left(\beta_{b j m}-\beta_{c j m}\right) f_{m t}^{R}+\left(\delta_{b j e}-1\right) v_{j e t}+v_{j i t} \\
& =\beta_{b j e}^{j} f_{e t}^{R}+\beta_{b j i}^{j} f_{i t}^{R}+\beta_{b j m}^{j} f_{m t}^{R}+\delta_{b j e}^{j} v_{j e t}+v_{j i t},
\end{aligned}
$$

\footnotetext{
${ }^{9}$ The price of risk coefficients obtained from the GARCH-in-mean-jump model are $\tau_{e}=0.0119, \tau_{i}=$ 0.1938 , and $\tau_{e}=0.0171$.

${ }^{10}$ From now on, I consider tests at the $5 \%$ level of significance.
} 
and similarly:

$$
\begin{aligned}
r_{s j t}^{j}= & \left(\beta_{s j e}-\beta_{c j e}\right) f_{e t}^{R}+\left(\beta_{s j i}-\beta_{c j i}\right) f_{i t}^{R}+\left(\beta_{s j m}-\beta_{c j m}\right) f_{m t}^{R} \\
& +\left(\delta_{s j e}-1\right) v_{j e t}+\delta_{s j i} v_{j i t}+v_{j m t} \\
= & \beta_{s j e}^{j} f_{e t}^{R}+\beta_{s j i}^{j} f_{i t}^{R}+\beta_{s j m}^{j} f_{m t}^{R}+\delta_{s j e}^{j} v_{j e t}+\delta_{s j i} v_{j i t}+v_{j m t} .
\end{aligned}
$$

Table $2 \mathrm{~b}$ presents the estimates of the factor loadings of local currency bond returns on each one of the common factors as well as those parameters related to the countryspecific exchange rate risk. In the first column, I find that the coefficient on the common exchange rate factor, $\beta_{b j e}^{j}$, is positive and significant only in China. As in the case of currency returns, this finding implies that local currency bond returns decrease (increase) when the dollar appreciates (depreciates). On the other hand, the negative and significant coefficient found in Thailand and Poland implies that the local currency bond returns in these two countries decrease when the dollar depreciates. In the second column, I find that bond returns are all positively correlated through the common interest rate factor. The coefficient $\beta_{b j i}^{j}$ is positive and statistically different from zero for all the countries. In the third column, the estimates of the factor loadings on the common residual market risk are significantly positive for Brazil, Venezuela, the Philippines and Russia. On the other hand, this coefficient is statistically negative for China and Poland. Note that the sensitivity of Chinese bond returns to common exchange rate movements is positive, while its sensitivity to idiosyncratic exchange rate movements is negative. As claimed in Sentana (2002), this difference in the sensitivity to common and idiosyncratic exchange rate risk is likely to reflect the structure of its foreign trade. Finally the fourth column reports the estimates of the factor loadings of bond returns on the idiosyncratic exchange rate factor, $\delta_{b j e}^{j}$. Here, the predominant sign is the negative one. In addition, all coefficients are statistically different from zero. Since the idiosyncratic exchange rate factor is the residual of the regression of the currency return on the three common factors, these negative coefficients imply that, taking the common factors as given, bond returns fall (rise) when the local currency appreciates (depreciates).

Table 2c reports the estimates of the factor loadings of local currency stock returns. In the first column, I find that the coefficient on the common exchange rate factor, $\beta_{s j e}^{j}$, is positive and significant for Brazil and the Philippines. In the second column, the estimates of the factor loadings on the common interest rate factor, $\beta_{s j i}^{j}$, are all positive and the coefficient is statistically significant for Argentina, Brazil, Mexico, Venezuela and Russia. In 
the third column, I find that all the coefficients on the common residual market factor, $\beta_{s j m}^{j}$, are positive and statistically differents from zero. The fourth column presents the estimates of the factor loadings of stock returns to the idiosyncratic exchange rate factor, $\delta_{s j e}^{j}$. These are statistically negative for Argentina, Venezuela and Russia. Thus, stock returns for these countries tend to fall (rise) when the local currency appreciates (depreciates). On the other

hand, $\delta_{s j e}^{j}$ is statistically positive for the Philippines. Finally, the fifth column reports the estimates of the factor loadings of stock returns on the idiosyncratic interest rate factor, $\delta_{s j i}^{j}$. Since these coefficients are positive with the exception of Poland (although, again, the coefficient is not significant), stock and bond returns seem to be positively correlated within a country.

\section{Direct effects of the exchange rate regime on the cost of capital}

A (credible) fixed exchange rate regime reduces the uncertainty induced by currency movements. Since the elimination of the exchange rate risk would reduce the risk premium, this reduction in the cost of capital will open new investment opportunities and will spur growth. However, there are several reasons these arguments might break down. For example, exchange rate risk may not be priced. Second, the monetary authority has to defend the level of the currency with the consequent increase of the interest rate volatility. If interest rate risk is also priced in stock returns, the increase of the interest rate risk can offset the gain obtained by the elimination of the exchange rate uncertainty.

Therefore, is the cost of capital lower in those countries that have adopted a fixed exchange rate regime? To address this question, I use a "de facto" classification of exchange rate regimes proposed by Levy-Yeyati and Sturzenegger (2003) (LYS from now on) to group the countries into those that have followed a fixed exchange rate system, and those that followed a floating one. In particular, and in line with these two authors, I expect this classification to provide a better characterization of the exchange rate policies, regardless of the regime reported by the country's authorities and published "de jure" by the International Monetary Fund. Following the LYS classification, I include Argentina, Brazil, Venezuela, China and Malaysia in the fixed exchange rate regime block; and Mexico, the Philippines, Thailand and Poland in the floating one. Russia has been dropped because its exchange rate regime has changed many times during the period of the study. 
Figure 1a displays the average of the (estimated) conditional standard deviation of the idiosyncratic exchange rate factor. The effect of the emerging markets crises is clear in the conditional volatility of the countries with fixed exchange rate regimes. There is no noticeable change in the magnitude of the movements of the volatility of those countries with a flexible exchange rate regime. In fact, the continual realignments of the currency peg (as in the case of Venezuela) or even its abandonment (Argentina and Brazil) has caused the level of the (idiosyncratic) volatility to be substantially larger for those countries that have fixed their exchange rates. Therefore, their exchange rate stabilisation polices have been unsuccessful. Equally important, Figure 1b presents the (estimated) conditional standard deviation of the idiosyncratic interest rate factor. The ranking is the same. The effect of financial turbulence is noticeable in both groups of countries, although it is more noticeable for those countries with a fixed exchange rate system. This means that not only has a fixed exchange rate regime been unable to reduce the exchange rate volatility in emerging markets, but it has also increased the interest rate volatility. This result is related to Calvo and Reinhart (2002). The lack of credibility of the fixed exchange rate regime has caused excess volatility in interest rates.

Still, the (idiosyncratic) movements should not be priced under the hypothesis of financial integration (see next section for more details). For this reason, I continue by testing whether, contrary to the theory, idiosyncratic exchange rate and interest rate risks are priced. Table 3 reports the tests on the pricing of country-specific volatility. The main results are the following. First, the exchange rate risk is priced in currency deposit returns for those countries with a flexible exchange rate regime. That is, the idiosyncratic exchange rate factor is more volatile for those countries with a fixed exchange rate regime (see Figure 1a), but it is not priced. Second, the exchange rate risk is priced in stock returns for those countries with a fixed exchange rate regime which implies that stock market investors demand compensation for the risk of a currency devaluation. Third, the interest rate risk is priced in (local currency) bond returns in those countries with a fixed exchange rate regime. Bond investors demand compensation for the excess volatility in interest rate caused by the defense of the level of the currency.

The analysis of the estimated sensitivities to the idiosyncratic risk factors, $\rho_{a j k}$ for $a=c, b, s$ and $k=e, i$, should give a good measure of the impact of the elimination of these country-specific risks. However, there are some problems with this approach. First, 
these (estimated) coefficients show great dispersion, being sometimes negative. Second and more important, the effects of idiosyncratic exchange rate and interest rate volatility may compensate each other. Therefore, I follow Sentana (2002) and measure the net effect of idiosyncratic exchange rate and interest rate movements on each asset by computing the differences in fitted values between the alternative and null hypothesis. This procedure has the advantage that each country acts as its own control.

The average net effect of idiosyncratic exchange rate volatility on currency returns across countries with a fixed and flexible exchange rate regime is presented in Figure 2a. Figures $2 \mathrm{~b}$ and $2 \mathrm{c}$ present the analogous net effect of idiosyncratic exchange rate and interest rate risks on bond and stocks returns, respectively. Furthermore, sample means and relevant Wald tests (robust to serial correlation and conditional heteroskedasticity) are reported in Table 4. Figure 2a shows that the net effect of idiosyncratic exchange rate volatility on currency returns is more important in those countries with a flexible exchange rate regime. In fact the difference between the effect in countries with a floating and a fixed exchange rate regime is positive most of the time. As shown in Table 4, this difference is significant at the $10 \%$ level. Figure $2 \mathrm{~b}$ shows a similar picture. The net effect of idiosyncratic exchange rate and interest rate volatility on bond returns seems to be more important in those countries with a flexible exchange rate regime. However, the difference is not statistically different from zero. Finally, the analysis of Figure 2c suggests that there is no clear effect of the exchange rate regime on (local currency) stock returns: the increase in the interest rate volatility seem to offset the decrease in the volatility of the idiosyncratic exchange rate factor. Therefore, since there is evidence that a fixed exchange rate regime reduces the currency risk premia demanded by foreign (U.S.) investors and foreign investment is an important source of emerging market financing, the tentative conclusion is that a fixed exchange rate regime system can help reduce the cost of capital of emerging market firms.

\section{$5 \quad$ Integration of emerging financial markets}

The hypothesis of market integration plays a central role in emerging market finance because it helps to identify the benefits of the process of liberalization that many emerging markets have followed. In particular, economic theory predicts that the process of financial liberalization will reduce the cost of capital (see Errunza and Losq, 1985). In this section, I retake the tests of pricing of idiosyncratic risks to analyze whether the hypothesis of market 
integration is valid in emerging financial markets.

The definition of international financial integration implies that assets with identical risk should command the same expected return regardless of their nationality. This means that no country-specific risk should be rewarded in a world of complete integration $\left(\rho_{a j k}=0\right.$ $\forall a=c, b, s \forall k=e, i, m)$; and, secondly, the price of (common) risk should be equal across countries $\left(\theta_{a j k}=0, \forall a=c, b, s \forall k=e, i, m\right)$. In section 4, I have examined whether idiosyncratic exchange and interest rate factors are priced for countries with a fixed and flexible exchange rate system as an exercise to analyze the impact of an exchange rate regime. Now, I repeat the analysis taking into account regional blocks, that is Latin America, Asia and East Europe, rather than exchange rate systems. I also include a test for the pricing of country-specific residual market risk and tests for the equality of the prices of common risks.

Table 5a reports the additional tests of market integration on the pricing of idiosyncratic risks. The findings are the following: First, the exchange rate risk is priced in the currency and stock returns of Latin America and Eastern Europe. It is only priced in bond returns of Eastern Europe. Second, the idiosyncratic interest rate risk is priced in the Asian bond returns at the ten percent level of significance. Finally, the idiosyncratic residual market risk is not priced in the equity market. On the other hand, Table 5b presents the tests for the equality of common risk prices. The analysis of this table suggests that prices of the (global) exchange rate, the interest rate and the residual market risks seem to be different in currency returns of Asia and Eastern Europe. The prices of the (global) exchange rate, the interest rate and the residual market risks are equal for bond and stock returns. Overall, the bond and stock markets seem to be integrated, while the currency market does not.

\subsection{Globalisation and the cost of capital}

Finally, I follow Stulz (1999) to measure the potential gains from the globalisation process by comparing the stock market risk premia under full integration with the risk premia that would prevail in the context of fully segmented markets. In particular, note that it is possible to decompose the unanticipated components of stock returns into three orthogonal components:

$$
\eta_{s j t}^{j}=\underbrace{\beta_{s j e}^{j} f_{e t}+\delta_{s j e}^{j}}_{\text {Exchange rate risk }} \underbrace{+\beta_{s j i}^{j} f_{i t}+\delta_{s j i}}_{\text {Interest rate risk }} \underbrace{+\beta_{s j m}^{j} f_{m t}+\delta_{s j m}}_{\text {Residual market risk }}
$$


Since the stock portfolio for each country corresponds to a well-diversified basket of domestic stocks one can obtain the risk premia that would prevail in this context using a domestic argument similar to the one presented in Section 2. In particular, this will result in the risk premia corresponding to a domestic APT pricing relationship:

$$
\begin{aligned}
\mu_{s j t}^{j s}= & \varphi_{j e}\left[\left(\beta_{s j e}^{j}\right)^{2} \lambda_{e t}+\left(\delta_{s j e}^{j}\right)^{2} \omega_{j e t}\right]+ \\
& +\varphi_{j i}\left[\left(\beta_{s j i}^{j}\right)^{2} \lambda_{i t}+\delta_{s j i}^{2} \omega_{j i t}\right]+\varphi_{j m}\left[\left(\beta_{s j m}^{j}\right)^{2} \lambda_{m t}+\delta_{s j m}^{2} \omega_{j m t}\right],
\end{aligned}
$$

where $\varphi_{j k}$ is the price of risk for country $j$ and factor $k=e, i, m$ in a fully segmented market framework. Assuming that all investors in the world have the same constant relative risk aversion, and that the price of the residual market risk and the statistical properties of asset returns are not affected by the globalisation process, I can compare the following risk premia:

$$
\begin{aligned}
\text { Risk premia under full integration } & =\tau_{m} \beta_{s j m}^{j} \lambda_{m t}, \\
\text { Risk premia under full segmentation } & =\varphi_{j m}\left[\left(\beta_{s j m}^{j}\right)^{2} \lambda_{m t}+\delta_{s j m}^{2} \omega_{j m t}\right] .
\end{aligned}
$$

Subsequently, I can assess whether there would be gains from a process of stock market integration, for each country comparing:

$$
\beta_{s j m} E\left[\lambda_{m t}\right] \lessgtr \beta_{s j m}^{2} E\left[\lambda_{m t}\right]+\delta_{s j m}^{2} E\left[\omega_{j m t}\right]
$$

The (estimated) differences between both sides of the above expression for each one of the emerging countries in the database are displayed in Table 6. Its analysis reveals ample evidence in favour of globalisation gains because these differences are all positive and significantly different from zero. Furthermore, there is an important variation across countries, where Russia is the country with the largest average, followed by China and Thailand. Moreover, if one multiplies these differences by 0.017 , which is the estimate of $\tau_{m}$, these results suggest that the globalisation gains can be rather large for these countries. On the other side, Mexico and Brazil are the countries with the smallest estimated gains. These two countries have significantly smaller idiosyncratic residual market risk variance (see Table 2c), and this suggests that they already have closer links with world markets. Finally, it is very important to emphasize that these gains should only be taken as indicative given that I am comparing two extreme situations. 


\section{Concluding remarks}

In this article I attempt to shed some light on two important questions in international finance: whether the choice of a fixed exchange rate regime is able to reduce the cost of capital and whether there are gains from the process of globalisation. For that reason, this paper presents a multifactor asset-pricing model that is estimated using weekly data on currency, bond and stock returns for ten emerging markets over the period from 4 June 1997 to 28 June 2006.

The findings in this paper suggest that not only has a fixed exchange rate regime been unable to reduce the exchange rate volatility in emerging markets, but it has also increased the interest rate volatility. This result is related to Calvo and Reinhart (2002). The lack of credibility of the fixed exchange rate regime has caused excess volatility in interest rates. However, there is evidence that a fixed exchange rate regime reduces the currency risk premia demanded by foreign investors. Therefore, the tentative conclusion is that a fixed exchange rate regime system can help reduce the cost of capital in emerging markets. In addition, the evidence against the hypothesis of integration of financial markets is mixed and depends on the market under examination. At the same time, I cannot reject the null hypothesis of the integration of emerging equity markets. A comparison between the risk premia that would prevail in a world of full integration and full segmentation reveals rather large gains from the process of liberalization of stock markets in some countries. 


\section{Appendix}

\section{A Database description}

Details of the data series used are as follows.

Short interest rates:

- Belgium, Denmark, France, Germany, Italy, Netherlands, Spain, Sweden, Switzerland, UK; Canada, Japan; Thailand: Euro-local currency 1 week.

- Argentina: Interbank 7 days - middle rate.

- Australia: Deposit 1 week.

- China: Demand deposit rate - middle rate.

- Brazil: CDI - Middle Rate.

- Malaysia, Poland: Interbank 1 week - middle rate.

- Mexico: Balance (TIIE) interbank rate.

- Philippines: Interbank call loan rate - middle rate.

- Russia: Interbank 2 to 7 days - middle rate.

- Venezuela: Overnight - middle rate

Bond returns:

- Belgium, Denmark, France, Germany, Italy, Netherlands, Spain, Sweden, Switzerland, UK; USA, Canada, Japan, Australia: Morgan Stanley Capital International Total Return Index (in local currency).

- Argentina, Brazil, Mexico, Venezuela; China, Malaysia, Philippines, Thailand; Poland, and Russia: J.P. Morgan EMBI Global Index (in U.S. dollars)

Stock prices:

- All countries: Morgan Stanley Capital International Return Index (in U.S. dollars)

\section{B Likelihood function of the GARCH-jump regres- sion model}

In this appendix, I provide the details of the likelihood function of the GARCH-jump regression model. As in Ball and Torous (1983), jumps are modeled by a mixture of two normal distributions where one state represents periods of calm, and the other one represents the state where a jump has occurred.

Assume that a stationary time series of returns $y_{t}(t=1, \ldots T)$ is observed and assume the following regression model:

$$
y_{t}=\mathbf{x}_{t}^{\prime} \boldsymbol{\beta}+\varepsilon_{t},
$$

where $\mathbf{x}_{t}^{\prime}$ denotes a vector of predetermined explanatory variables (i.e. the returns of the factor representing portfolios $\mathbf{f}_{t}^{R}$ ). The disturbance term $\varepsilon_{t}$ is assumed to satisfy, conditional 
on past information $\psi_{t-1}$ and the predetermined variables $\mathbf{x}_{t}^{\prime}$, a mixture of two normal distributions which implies that the conditional density of $\varepsilon_{t}$ is given by:

$$
f\left(\varepsilon_{t} \mid \psi_{t-1}, \mathbf{x}_{t}^{\prime}\right)=(1-\lambda) \phi\left(\varepsilon_{t} ; \lambda \mu, \sigma_{t}^{2}\right)+\lambda \phi\left(\varepsilon_{t} ;-(1-\lambda) \mu, \sigma_{t}^{2}+\delta\right),
$$

where $\phi(\cdot)$ is the density function of the normal distribution and $\lambda$ is the mixing weight. That is, with probability $1-\lambda$ the error term $\varepsilon_{t}$ is conditionally normal with mean $\lambda \mu$ and time-varying volatility $\sigma_{t}^{2}$; while with probability $\lambda, \varepsilon_{t}$ is normal with mean - $(1-$ $\lambda) \mu$ and time-varying volatility $\sigma_{t}^{2}+\delta$. Note that this structure guarantees that $\varepsilon_{t}$ is an innovation because it has conditional expectation equal to zero $E\left[\varepsilon_{t} \mid \psi_{t-1}, \mathbf{x}_{t}^{\prime}\right]=0$, while the conditional variance of $\varepsilon_{t}$ is given by:

$$
\operatorname{Var}\left[\varepsilon_{t} \mid \psi_{t-1}, \mathbf{x}_{t}^{\prime}\right]=(1-\lambda)\left[\sigma_{t}^{2}+\lambda^{2} \mu^{2}\right]+\lambda\left[\sigma_{t}^{2}+\delta+(1-\lambda)^{2} \mu^{2}\right] .
$$

In addition, the parameters are restricted to identify the second state with the intuition that exists behind the definition of a jump. In particular, I impose $\mu>0$ (the jump implies, in mean, a negative return), $\delta>0$ (the jump increases the conditional volatility of the returns) and $\lambda<\frac{1}{2}$ (a jump is less likely to occur than the state of calm).

The model is completed with the equation that rules the evolution of the conditional volatility during calm periods. Here and in the spirit of Vlaar and Palm (1993), I assume that $\sigma_{t}^{2}$ follows a $\operatorname{GARCH}(1,1)$ process:

$$
\sigma_{t}^{2}=\alpha_{0}+\alpha_{1} \varepsilon_{t-1}^{2}+\alpha_{2} \sigma_{t-1}^{2}
$$

It is worth noting that Haas et al. (2004) have shown that this model is a special case of their $k$-component mixed normal $\operatorname{GARCH}(p, q)$ process. The reader is referred to their work for the analysis of the stationarity and persistence properties of these conditional heteroskedastic mixed normal processes. Moreover, I use their formulae to compute the unconditional expectation of $\sigma_{t}^{2}$ and, therefore, to initialize the recursion in the GARCH equation.

Finally, the analysis can be easily extended to introduce the GARCH-in-mean-Jump regression model. In particular, if I denote $\omega_{t}^{2}=\operatorname{Var}\left[\varepsilon_{t} \mid \psi_{t-1}, \mathbf{x}_{t}^{\prime}\right]$ as the conditional variance of the error term, I only need to modify the definition of the error term in (10) in the following way:

$$
y_{t}=\mathbf{x}_{t}^{\prime} \boldsymbol{\beta}+\tau \omega_{t}^{2}+\varepsilon_{t},
$$

where $\tau$ captures the impact of the conditional variance on the expected returns.

\section{References}

[1] Ball, C.A. and W. N. Torous (1983): "A Simplified Jump Process for Common Stock Returns", Journal of Financial and Quantitative Analysis 18, 53-65. 
[2] Bollerslev, T. and J. M. Wooldridge (1992): "Quasi-Maximum Likelihood Estimation and Inference in Dynamic Models with Time-Varying Variances", Econometric Reviews, 11, 143-72.

[3] Calvo, G. and C. M. Reinhart (2002): "Fear of Floating", Quarterly Journal of Economics, 117, 2, 379-408.

[4] Chamberlain, G. and M. Rothschild (1983): "Arbitrage, Factor Structure, and MeanVariance Analysis on Large Asset Markets", Econometrica, 51, 1281-304.

[5] Cochrane, J.H. (2001): Asset Pricing. Princeton, Princeton University Press.

[6] Das, S. R. (2002): "The Surprise Element: Jumps in Interest Rates", Journal of Econometrics, 106, 27-65.

[7] Department of the Treasury (2003): Report on U.S. Holdings of Foreign Securities

[8] Errunza, V. and E. Losq (1985): "International Asset Pricing under Mild Segmentation: Theory and Test", Journal of Finance, 40, 105-124.

[9] Haas M., S. Mittnik and M.S. Paolella (2004): "Mixed Normal Conditional Heteroskedasticity", Journal of Financial Econometrics, 2, 211-250.

[10] Jorion, P. (1988): "On Jump Processes in the Foreign Exchange and Stock Markets", Review of Financial Studies, 1,4, 427-445.

[11] King, M., E. Sentana and S. Wadhwani (1994): "Volatility and Links Between National Stock Markets", Econometrica, 62,4, 901-933.

[12] Levy-Yeyati, E. and F. Sturzenegger (2003): "To Float or to Trail: Evidence on the Impact of Exchange Rate Regimes", American Economic Review, 93, 1173-93.

[13] Newey, W. and K.D. West (1987): "A Simple Positive Semi-Definite Heteroskedasticity and Autocorrelation Consistent Covariance Matrix", Econometrica 55, 703-6.

[14] Pavlova, A. and R. Rigobon (2006): "Asset Prices and Exchange Rates", forthcoming Review of Financial Studies.

[15] Reinhart, C. M. and K. S. Rogoff (2004): "The Modern History of Exchange Rate Arrangements: A Reinterpretation", Quarterly Journal of Economics, 119, 1-48.

[16] Rigobon, R. (2003): "Identification Through Heteroskedasticity", Review of Economics and Statistics, 85, 777-792.

[17] Sentana, E. (2002): "Did the EMS Reduce the Cost of Capital?", Economic Journal, 112, 786-809. 
[18] Sentana, E. and G. Fiorentini (2001): "Identification, Estimation and Testing of Conditionally Heteroskedastic Factor Models", Journal of Econometrics, 102, 143-164.

[19] Stulz, R. (1999): "Globalization of Equity Markets and the Cost of Capital", Dice Center WP 99-1, Ohio State University.

[20] Vlaar, P.J.G and F.C. Palm (1993): "The Message in Weekly Exchange Rates in the European Monetary System: Mean Reversion, Conditional Heteroskedasticity, and Jumps", Journal of Business and Economic Statistics 11, 351-60. 
Table 1

Prices of risk and factor loadings for world portfolios

\begin{tabular}{ccccc}
\hline $\begin{array}{c}\text { World } \\
\text { portfolio }\end{array}$ & $\begin{array}{c}\text { Common exchange } \\
\text { rate risk }\end{array}$ & $\begin{array}{c}\text { Common interest } \\
\text { rate risk }\end{array}$ & $\begin{array}{c}\text { Common stock } \\
\text { market risk }\end{array}$ & $\begin{array}{c}\text { Unconditional } \\
\text { variances }\end{array}$ \\
\hline Currencies & $\beta_{\text {cpe }}^{\$}=1$ & & & $\lambda_{e}=0.602^{* * *}$ \\
& & & & $(0.073)$ \\
Bonds & $\beta_{b p e}^{\$}=0.887^{* * *}$ & $\beta_{b p i}=1$ & & $\lambda_{i}=0.488^{* * *}$ \\
& $(0.078)$ & & & $(0.0932)$ \\
Stocks & $\beta_{\text {spe }}^{\$}=0.945^{* * *}$ & $\beta_{s p i}=0.763^{* * *}$ & $\beta_{s p m}=1$ & $\lambda_{m}=5.160^{* * *}$ \\
& $(0.172)$ & $(0.286)$ & & $(0.572)$ \\
\hline & $\pi_{e}=-0.001$ & $\pi_{i}=0.0653^{*}$ & $\pi_{m}=0.018$ & \\
& $(0.036)$ & $(0.036)$ & $(0.118)$ & \\
\hline
\end{tabular}

Note: GMM estimates of equation (4):

$$
\mathbf{r}_{p t}=\mathbf{B}_{p} \mathbf{f}_{t}^{R}, \pi_{k}=E\left(\pi_{k t}\right), \lambda_{k}=E\left(\lambda_{k t}\right)=V\left(f_{k t}\right)(k=e, i, m)
$$

Newey-West (1987) heteroskedasticity and autocorrelation robust S.E in parentheses. $\left.{ }^{* * *}\right),\left({ }^{* *}\right),\left({ }^{*}\right)$ indicates coefficient significantly different from zero at the $1 \%, 5 \%$ and $10 \%$ level, respectively. Sample period: 4 June 1997 - 28 June 2006 (474 observations). 
Table 2a

Factor loadings for currency returns $(\$)$

\begin{tabular}{lcccc}
\hline Country & $\begin{array}{c}\text { Common } \\
\text { exch. rate } \\
\text { risk }\left(\beta_{c j e}\right)\end{array}$ & $\begin{array}{c}\text { Common } \\
\text { int. rate } \\
\text { risk }\left(\beta_{c j i}\right)\end{array}$ & $\begin{array}{c}\text { Common } \\
\text { market } \\
\text { risk }\left(\beta_{c j m}\right)\end{array}$ & $\begin{array}{c}\text { Idiosyncratic } \\
\text { variance } \\
\left(\omega_{j e}\right)\end{array}$ \\
\hline Argentina & 0.674 & -0.657 & $0.130^{* *}$ & $9.102^{*}$ \\
& $(0.428)$ & $(0.508)$ & $(0.063)$ & $(5.193)$ \\
Brazil & $0.922^{* * *}$ & 0.067 & $0.258^{* * *}$ & $6.652^{* * *}$ \\
& $(0.271)$ & $(0.225)$ & $(0.087)$ & $(2.021)$ \\
Mexico & $0.239^{* *}$ & $0.402^{* * *}$ & $0.188^{* * *}$ & $1.156^{* * *}$ \\
& $(0.106)$ & $(0.134)$ & $(0.027)$ & $(0.127)$ \\
Venezuela & $0.681^{* * *}$ & $-0.820^{*}$ & 0.079 & $12.404^{* * *}$ \\
& $(0.237)$ & $(0.433)$ & $(0.049)$ & $(4.947)$ \\
China & & & & \\
Malaysia & $0.012^{* * *}$ & -0.008 & 0.002 & 0.012 \\
& $(0.005)$ & $(0.006)$ & $(0.002)$ & $(0.008)$ \\
Philippines & $0.732^{* * *}$ & $-0.575^{* * *}$ & 0.045 & $5.316^{* *}$ \\
& $(0.251)$ & $(0.211)$ & $(0.040)$ & $(2.549)$ \\
Thailand & $0.551^{* * *}$ & -0.228 & $0.132^{* * *}$ & $2.404^{* * *}$ \\
& $(0.162)$ & $(0.193)$ & $(0.035)$ & $(0.692)$ \\
& $0.777^{* * *}$ & -0.208 & $0.151^{* * *}$ & $2.708^{* * *}$ \\
& $(0.176)$ & $(0.191)$ & $(0.053)$ & $(0.790)$ \\
Poland & & & & \\
& $1.221^{* * *}$ & $0.450^{* * *}$ & $0.097^{* * *}$ & $1.272^{* * *}$ \\
& $(0.129)$ & $(0.102)$ & $(0.027)$ & $(0.176)$ \\
& 2.240 & -1.707 & 0.039 & 26.448 \\
& $(1.721)$ & $(1.311)$ & $(0.078)$ & $(20.137)$ \\
\hline
\end{tabular}

Note: GMM estimates of eq (4a):

$$
r_{c j t}=\beta_{c j e} f_{e t}^{R}+\beta_{c j i} f_{i t}^{R}+\beta_{c j m} f_{m t}^{R}+v_{j e t}, \omega_{j e}=E\left(\omega_{j e t}\right)=V\left(v_{j e t}\right)
$$

Newey-West (1987) heteroskedasticity and autocorrelation robust S.E in parentheses. $\left(^{(* *}\right),\left({ }^{* *}\right),\left({ }^{*}\right)$ indicates coefficient significantly different from zero at the 1\%, $5 \%$ and $10 \%$ level, respectively. Sample period: 4 June 1997 - 28 June 2006 (474 observations). 
Table 2b

Factor loadings for bond returns (local currency)

\begin{tabular}{lccccc}
\hline Country & $\begin{array}{c}\text { Common } \\
\text { exch. rate } \\
\text { risk }\left(\beta_{b j e}^{j}\right)\end{array}$ & $\begin{array}{c}\text { Common } \\
\text { int. rate } \\
\text { risk }\left(\beta_{b j i}^{j}\right)\end{array}$ & $\begin{array}{c}\text { Common } \\
\text { market } \\
\text { risk }\left(\beta_{b j m}^{j}\right)\end{array}$ & $\begin{array}{c}\text { Specific } \\
\text { exch. rate } \\
\text { risk }\left(\delta_{b j e}^{j}\right)\end{array}$ & $\begin{array}{c}\text { Idiosyncratic } \\
\text { variance } \\
\left(\omega_{j i}\right)\end{array}$ \\
\hline Argentina & 0.050 & $2.798^{* * *}$ & 0.146 & $-0.832^{* * *}$ & $7.412^{* * *}$ \\
& $(0.416)$ & $(0.611)$ & $(0.092)$ & $(0.063)$ & $(1.848)$ \\
Brazil & -0.090 & $2.040^{* * *}$ & $0.244^{* * *}$ & $-0.545^{* * *}$ & $4.097^{* * *}$ \\
& $(0.230)$ & $(0.465)$ & $(0.077)$ & $(0.098)$ & $(0.977)$ \\
Mexico & 0.065 & $0.893^{* * *}$ & -0.016 & $-0.655^{* * *}$ & $0.601^{* * *}$ \\
& $(0.117)$ & $(0.075)$ & $(0.025)$ & $(0.061)$ & $(0.105)$ \\
Venezuela & -0.147 & $2.737^{* * *}$ & $0.227^{* * *}$ & $-0.976^{* * *}$ & $3.332^{* * *}$ \\
& $(0.291)$ & $(0.447)$ & $(0.058)$ & $(0.035)$ & $(0.649)$ \\
& & & & & \\
China & $0.143^{* * *}$ & $0.542^{* * *}$ & $-0.079^{* * *}$ & $-1.329^{* * *}$ & $0.275^{* * *}$ \\
Malaysia & $(0.053)$ & $(0.087)$ & $(0.012)$ & $(0.140)$ & $(0.046)$ \\
& -0.388 & $1.401^{* * *}$ & -0.047 & $-1.072^{* * *}$ & $1.468^{* *}$ \\
Philippines & $(0.341)$ & $(0.310)$ & $(0.047)$ & $(0.064)$ & $(0.712)$ \\
& -0.171 & $1.279^{* * *}$ & $0.106^{* * *}$ & $-0.809^{* * *}$ & $1.036^{* * *}$ \\
Thailand & $(0.188)$ & $(0.229)$ & $(0.038)$ & $(0.056)$ & $(0.131)$ \\
& $-0.625^{* * *}$ & $1.365^{* * *}$ & -0.053 & $-0.845^{* * *}$ & $1.259^{* * *}$ \\
& $(0.173)$ & $(0.201)$ & $(0.045)$ & $(0.039)$ & $(0.360)$ \\
Poland & & & & & \\
& $-0.998^{* * *}$ & $0.504^{* * *}$ & $-0.078^{* * *}$ & $-0.988^{* * *}$ & $0.412^{* * *}$ \\
& $(0.139)$ & $(0.142)$ & $(0.029)$ & $(0.034)$ & $(0.053)$ \\
& -1.795 & $5.827^{* * *}$ & $0.595^{* * *}$ & $-0.908^{* * *}$ & $11.837^{* * *}$ \\
& $(1.955)$ & $(1.689)$ & $(0.085)$ & $(0.059)$ & $(3.169)$ \\
\hline
\end{tabular}

Note: GMM estimates of eq (5):

$$
r_{b j t}^{j}=\beta_{b j e}^{j} f_{e t}^{R}+\beta_{b j i}^{j} f_{i t}^{R}+\beta_{b j m}^{j} f_{m t}^{R}+\delta_{b j e}^{j} v_{j e t}+v_{j i t}, \omega_{j i}=E\left(\omega_{j i t}\right)=V\left(v_{j i t}\right)
$$

Newey-West (1987) heteroskedasticity and autocorrelation robust S.E in parentheses. $\left(^{(* *}\right),\left({ }^{* *}\right),\left({ }^{*}\right)$ indicates coefficient significantly different from zero at the 1\%, $5 \%$ and $10 \%$ level, respectively. Sample period: 4 June 1997 - 28 June 2006 (474 observations). 
Table 2c

Factor loadings for stock returns (local currency)

\begin{tabular}{|c|c|c|c|c|c|c|}
\hline Country & $\begin{array}{l}\text { Common } \\
\text { exch. rate } \\
\text { risk }\left(\beta_{s j e}^{j}\right)\end{array}$ & $\begin{array}{l}\text { Common } \\
\text { int. rate } \\
\text { risk }\left(\beta_{s j i}^{j}\right)\end{array}$ & $\begin{array}{c}\text { Common } \\
\text { market } \\
\text { risk }\left(\beta_{s j m}^{j}\right)\end{array}$ & $\begin{array}{l}\text { Specific } \\
\text { exch. rate } \\
\text { risk }\left(\delta_{s j e}^{j}\right)\end{array}$ & $\begin{array}{c}\text { Specific } \\
\text { int. rate } \\
\text { risk }\left(\delta_{s j i}\right)\end{array}$ & $\begin{array}{c}\text { Idiosyncratic } \\
\text { variance } \\
\left(\omega_{j m}\right)\end{array}$ \\
\hline Argentina & $\begin{array}{c}0.398 \\
(0.540)\end{array}$ & $\begin{array}{c}2.295^{* * *} \\
(0.522)\end{array}$ & $\begin{array}{c}1.041^{* * *} \\
(0.106)\end{array}$ & $\begin{array}{c}-0.864^{* * *} \\
(0.151)\end{array}$ & $\begin{array}{c}0.269 \\
(0.177)\end{array}$ & $\begin{array}{c}18.764^{* * *} \\
(3.574)\end{array}$ \\
\hline Brazil & $\begin{array}{c}1.195^{* * *} \\
(0.313)\end{array}$ & $\begin{array}{c}2.225^{* * *} \\
(0.672)\end{array}$ & $\begin{array}{c}1.075^{* * *} \\
(0.093)\end{array}$ & $\begin{array}{l}-0.166 \\
(0.119)\end{array}$ & $\begin{array}{c}0.948^{* * *} \\
(0.104)\end{array}$ & $\begin{array}{c}7.934^{* * *} \\
(0.904)\end{array}$ \\
\hline Mexico & $\begin{array}{c}0.395 \\
(0.244)\end{array}$ & $\begin{array}{c}1.374^{* * *} \\
(0.385)\end{array}$ & $\begin{array}{c}1.074^{* * *} \\
(0.060)\end{array}$ & $\begin{array}{c}0.192 \\
(0.126)\end{array}$ & $\begin{array}{c}0.948^{* * *} \\
(0.150)\end{array}$ & $\begin{array}{c}5.462^{* * *} \\
(0.596)\end{array}$ \\
\hline Venezuela & $\begin{array}{l}-0.138 \\
(0.311)\end{array}$ & $\begin{array}{c}2.004^{* * *} \\
(0.422)\end{array}$ & $\begin{array}{c}0.779^{* * *} \\
(0.103)\end{array}$ & $\begin{array}{c}-0.169^{* *} \\
(0.075)\end{array}$ & $\begin{array}{c}0.873^{* * *} \\
(0.151)\end{array}$ & $\begin{array}{c}21.422^{* * *} \\
(3.368)\end{array}$ \\
\hline China & $\begin{array}{l}0.613^{*} \\
(0.316)\end{array}$ & $\begin{array}{c}0.200 \\
(0.500)\end{array}$ & $\begin{array}{c}1.225^{* * *} \\
(0.110)\end{array}$ & $\begin{array}{c}1.242 \\
(1.419)\end{array}$ & $\begin{array}{c}0.622 \\
(0.443)\end{array}$ & $\begin{array}{c}18.799^{* * *} \\
(2.301)\end{array}$ \\
\hline Malaysia & $\begin{array}{l}-0.037 \\
(0.405)\end{array}$ & $\begin{array}{c}0.482 \\
(0.524)\end{array}$ & $\begin{array}{c}0.800^{* * *} \\
(0.133)\end{array}$ & $\begin{array}{l}-0.254 \\
(0.350)\end{array}$ & $\begin{array}{c}0.249 \\
(0.613)\end{array}$ & $\begin{array}{c}19.362^{* * *} \\
(4.877)\end{array}$ \\
\hline Philippines & $\begin{array}{c}0.605^{* * *} \\
(0.219)\end{array}$ & $\begin{array}{c}0.292 \\
(0.371)\end{array}$ & $\begin{array}{c}0.736^{* * *} \\
(0.107)\end{array}$ & $\begin{array}{c}0.632^{* * *} \\
(0.151)\end{array}$ & $\begin{array}{c}0.525^{* * *} \\
(0.123)\end{array}$ & $\begin{array}{c}10.249^{* * *} \\
(0.928)\end{array}$ \\
\hline Thailand & $\begin{array}{c}0.320 \\
(0.302)\end{array}$ & $\begin{array}{c}0.991 \\
(0.444)\end{array}$ & $\begin{array}{c}1.221^{* * *} \\
(0.112)\end{array}$ & $\begin{array}{l}0.423^{* *} \\
(0.200)\end{array}$ & $\begin{array}{c}0.187 \\
(0.245)\end{array}$ & $\begin{array}{c}18.548^{* * *} \\
(2.461)\end{array}$ \\
\hline Poland & $\begin{array}{l}-0.203 \\
(0.314)\end{array}$ & $\begin{array}{c}0.246 \\
(0.363)\end{array}$ & $\begin{array}{c}1.025^{* * *} \\
(0.089)\end{array}$ & $\begin{array}{c}0.203 \\
(0.138)\end{array}$ & $\begin{array}{l}-0.330 \\
(0.293)\end{array}$ & $\begin{array}{c}10.686^{* * *} \\
(1.059)\end{array}$ \\
\hline Russia & $\begin{array}{l}-1.177 \\
(1.875)\end{array}$ & $\begin{array}{c}4.201^{* * *} \\
(1.327)\end{array}$ & $\begin{array}{c}1.715^{* * *} \\
(0.165)\end{array}$ & $\begin{array}{c}-0.847^{* * *} \\
(0.057)\end{array}$ & $\begin{array}{c}0.683^{\text {*** }} \\
(0.136)\end{array}$ & $\begin{array}{c}35.490^{* * *} \\
(5.501)\end{array}$ \\
\hline
\end{tabular}

Note: GMM estimates of eq. (7):

$$
r_{s j t}^{j}=\beta_{s j e}^{j} f_{e t}^{R}+\beta_{s j i}^{j} f_{i t}^{R}+\beta_{s j m}^{j} f_{m t}^{R}+\delta_{s j e}^{j} v_{j e t}+\delta_{s j i} v_{j i t}+v_{j m t}, \omega_{j m}=E\left(\omega_{j m t}\right)=V\left(v_{j m t}\right)
$$

Newey-West (1987) heteroskedasticity and autocorrelation robust S.E in parentheses. $\left(^{(* *}\right),\left({ }^{* *}\right),\left({ }^{*}\right)$ indicates coefficient significantly different from zero at the 1\%, $5 \%$ and $10 \%$ level, respectively. Sample period: 4 June 1997 - 28 June 2006 (474 observations). 
Table 3

Wald Tests for pricing of idiosyncratic exchange rate and interest rates risks

\begin{tabular}{llcccc}
\hline $\begin{array}{l}\text { Null } \\
\text { Hypothesis }\end{array}$ & Risk & Asset & Fixed & Floating \\
\hline$\rho_{c j e}=0$ & $\forall j$ & Exchange rate & Currencies & 7.959 & 14.293 \\
& & & & {$[0.159]$} & {$[0.006]$} \\
$\rho_{b j e}^{j}=0$ & $\forall j$ & \multirow{2}{*}{ Exchange rate } & \multirow{2}{*}{ Bonds } & 5.664 & 2.404 \\
& & & & {$[0.340]$} & {$[0.662]$} \\
$\rho_{s j e}^{j}=0$ & \multirow{2}{*}{$\forall j$} & Exchange rate & \multirow{2}{*}{ Stocks } & 11.661 & 2.132 \\
& & & & {$[0.040]$} & {$[0.711]$} \\
$\rho_{b j i}^{j}=0$ & \multirow{2}{*}{$\forall j$} & \multirow{2}{*}{ Interest rate } & \multirow{2}{*}{ Bonds } & 9.855 & 5.377 \\
& & & & {$[0.079]$} & {$[0.251]$} \\
$\rho_{s j i}^{j}=0$ & $\forall j$ & \multirow{2}{*}{ Interest rate } & \multirow{2}{*}{ Stocks } & 1.016 & 1.503 \\
& & & & {$[0.961]$} & {$[0.826]$} \\
\hline
\end{tabular}

Note: Newey-West (1987) heteroskedasticity and autocorrelation robust S.E. Sample period: 4 June 1997 - 28 June 2006 (474 observations). 
Table 4

Net effect of idiosyncratic exchange and interest rate volatility on returns

\begin{tabular}{llccc}
\hline Asset & Countries & Average & Wald & p-value \\
\hline Currencies (\$) & Fixed & -0.015 & 0.202 & 0.653 \\
& Flexible & 0.073 & 4.567 & 0.033 \\
& Difference & 0.087 & 3.737 & 0.053 \\
& & & & \\
Bonds (l.c.) & Fixed & -0.020 & 0.206 & 0.650 \\
& Flexible & 0.055 & 3.807 & 0.051 \\
& Difference & 0.075 & 1.878 & 0.171 \\
& & & & \\
Stocks (l.c.) & Fixed & -0.002 & 0.001 & 0.982 \\
& Flexible & -0.055 & 0.331 & 0.565 \\
& Difference & -0.053 & 0.223 & 0.637 \\
\hline
\end{tabular}

Note: GMM estimates with Newey-West (1987) heteroskedasticity and autocorrelation robust S.E. Sample period: 4 June 1997 - 28 June 2006 (474 observations). 
Table 5

\section{Additional tests of market integration}

Panel a: Test for pricing of idiosyncratic risks

\begin{tabular}{|c|c|c|c|c|c|}
\hline Null & & & Latin & & Eastern \\
\hline Hypothesis & Risk & Asset & America & Asia & Europe \\
\hline$\rho_{c j e}=0 \quad \forall j$ & Exchange rate & Currencies & 13.832 & 1.898 & 8.952 \\
\hline & & & {$[0.008]$} & {$[0.755]$} & {$[0.011]$} \\
\hline$\rho_{b j e}^{j}=0 \quad \forall j$ & Exchange rate & Bonds & 2.421 & 5.299 & 26.102 \\
\hline & & & {$[0.659]$} & {$[0.258]$} & {$[0.000]$} \\
\hline$\rho_{s j e}^{j}=0 \quad \forall j$ & Exchange rate & Stocks & 9.858 & 3.948 & 6.334 \\
\hline & & & {$[0.043]$} & {$[0.413]$} & {$[0.042]$} \\
\hline$\rho_{b j i}^{j}=0 \quad \forall j$ & Interest rate & Bonds & 5.078 & 8.303 & 2.661 \\
\hline & & & {$[0.279]$} & {$[0.081]$} & {$[0.264]$} \\
\hline$\rho_{s j i}^{j}=0 \quad \forall j$ & Interest rate & Stocks & 1.343 & 0.197 & 1.396 \\
\hline & & & {$[0.854]$} & {$[0.996]$} & {$[0.498]$} \\
\hline$\rho_{s j m}^{j}=0 \quad \forall j$ & Residual market & Stocks & 0.319 & 3.799 & 0.809 \\
\hline & & & [0.989] & {$[0.434]$} & {$[0.667]$} \\
\hline
\end{tabular}

Panel b: Test for equality of common risk prices

\begin{tabular}{|c|c|c|c|c|c|c|}
\hline Null & & & & Latin & & Eastern \\
\hline Hypothesi & & Risk & Asset & America & Asia & Europe \\
\hline$\theta_{c j e}=0$ & $\forall j$ & Exchange rate & Currencies & 7.119 & 58.636 & 9.162 \\
\hline & & & & {$[0.130]$} & {$[0.000]$} & {$[0.010]$} \\
\hline$\theta_{b j e}^{j}=0$ & $\forall j$ & Exchange rate & Bonds & 7.247 & 2.423 & 0.815 \\
\hline & & & & {$[0.123]$} & [0.659] & {$[0.665]$} \\
\hline$\theta_{s j e}^{j}=0$ & $\forall j$ & Exchange rate & Stocks & 3.569 & 5.224 & 0.982 \\
\hline & & & & {$[0.468]$} & {$[0.265]$} & {$[0.612]$} \\
\hline$\theta_{b j i}=0$ & $\forall j$ & Interest rate & Currencies & 2.417 & 40.290 & 6.424 \\
\hline & & & & {$[0.660]$} & {$[0.000]$} & {$[0.040]$} \\
\hline$\theta_{b j i}^{j}=0$ & $\forall j$ & Interest rate & Bonds & 2.779 & 4.305 & 2.523 \\
\hline & & & & {$[0.596]$} & {$[0.366]$} & {$[0.283]$} \\
\hline$\theta_{s j i}^{j}=0$ & $\forall j$ & Interest rate & Stocks & 7.998 & 1.316 & 3.952 \\
\hline & & & & {$[0.092]$} & {$[0.859]$} & {$[0.139]$} \\
\hline$\theta_{c j m}=0$ & $\forall j$ & Residual market & Currencies & 6.595 & 60.833 & 5.154 \\
\hline & & & & {$[0.159]$} & {$[0.000]$} & {$[0.076]$} \\
\hline$\theta_{b j m}^{j}=0$ & $\forall j$ & Residual market & Bonds & 3.503 & 2.362 & 0.867 \\
\hline & & & & {$[0.477]$} & {$[0.670]$} & [0.648] \\
\hline$\theta_{s j m}^{j}=0$ & $\forall j$ & Residual market & Stocks & 8.384 & 3.474 & 0.391 \\
\hline & & & & {$[0.079]$} & {$[0.482]$} & [0.823] \\
\hline
\end{tabular}

Note: Newey-West (1987) heteroskedasticity and autocorrelation robust S.E. Sample period: 4 June 1997 - 28 June 2006 (474 observations). 
Table 6

Average gains from stock market integration

\begin{tabular}{lccc}
\hline Country & $\beta_{s j m}^{2} \lambda_{m}+\omega_{j m}$ & $\beta_{s j m} \lambda_{m}$ & Difference \\
\hline Argentina & $24.351^{* * *}$ & $5.370^{* * *}$ & $18.981^{* * *}$ \\
& $(3.326)$ & $(0.761)$ & $(3.375)$ \\
Brazil & $13.902^{* * *}$ & $5.549^{* * *}$ & $8.352^{* * *}$ \\
& $(1.616)$ & $(0.694)$ & $(1.048)$ \\
Mexico & $11.414^{* * *}$ & $5.542^{* * *}$ & $5.872^{* * *}$ \\
& $(1.012)$ & $(0.580)$ & $(0.671)$ \\
Venezuela & $24.551^{* * *}$ & $4.018^{* * *}$ & $20.533^{* * *}$ \\
& $(3.615)$ & $(0.609)$ & $(3.404)$ \\
& & & \\
China & $26.542^{* * *}$ & $6.321^{* * *}$ & $20.221^{* * *}$ \\
& $(3.184)$ & $(0.833)$ & $(2.676)$ \\
Malaysia & $22.668^{* * *}$ & $4.130^{* * *}$ & $18.538^{* * *}$ \\
& $(5.854)$ & $(0.803)$ & $(5.142)$ \\
Philippines & $13.041^{* * *}$ & $3.796^{* * *}$ & $9.246^{* * *}$ \\
& $(1.339)$ & $(0.610)$ & $(0.969)$ \\
Thailand & $26.236^{* * *}$ & $6.298^{* * *}$ & $19.937^{* * *}$ \\
& $(3.229)$ & $(0.712)$ & $(2.858)$ \\
& & & \\
Poland & $16.110^{* * *}$ & $5.290^{* * *}$ & $10.819^{* * *}$ \\
& $(1.597)$ & $(0.705)$ & $(1.124)$ \\
Russia & $50.671^{* * *}$ & $8.851^{* * *}$ & $41.820^{* * *}$ \\
& $(7.360)$ & $(1.135)$ & $(6.570)$ \\
\hline
\end{tabular}

Note: GMM estimates with Newey-West (1987) heteroskedasticity and autocorrelation robust S.E in parantheses. $\left({ }^{* * *}\right),\left({ }^{* *}\right),\left({ }^{*}\right)$ indicates coefficient significantly different from zero at the $1 \%$, $5 \%$ and 10\% level, respectively. Sample period 4 June 1997 - 28 June 2006 (474 observations). 
Figure 1

(a) Average Conditional Standard Deviation of Idiosyncratic Exchange Rate Factors

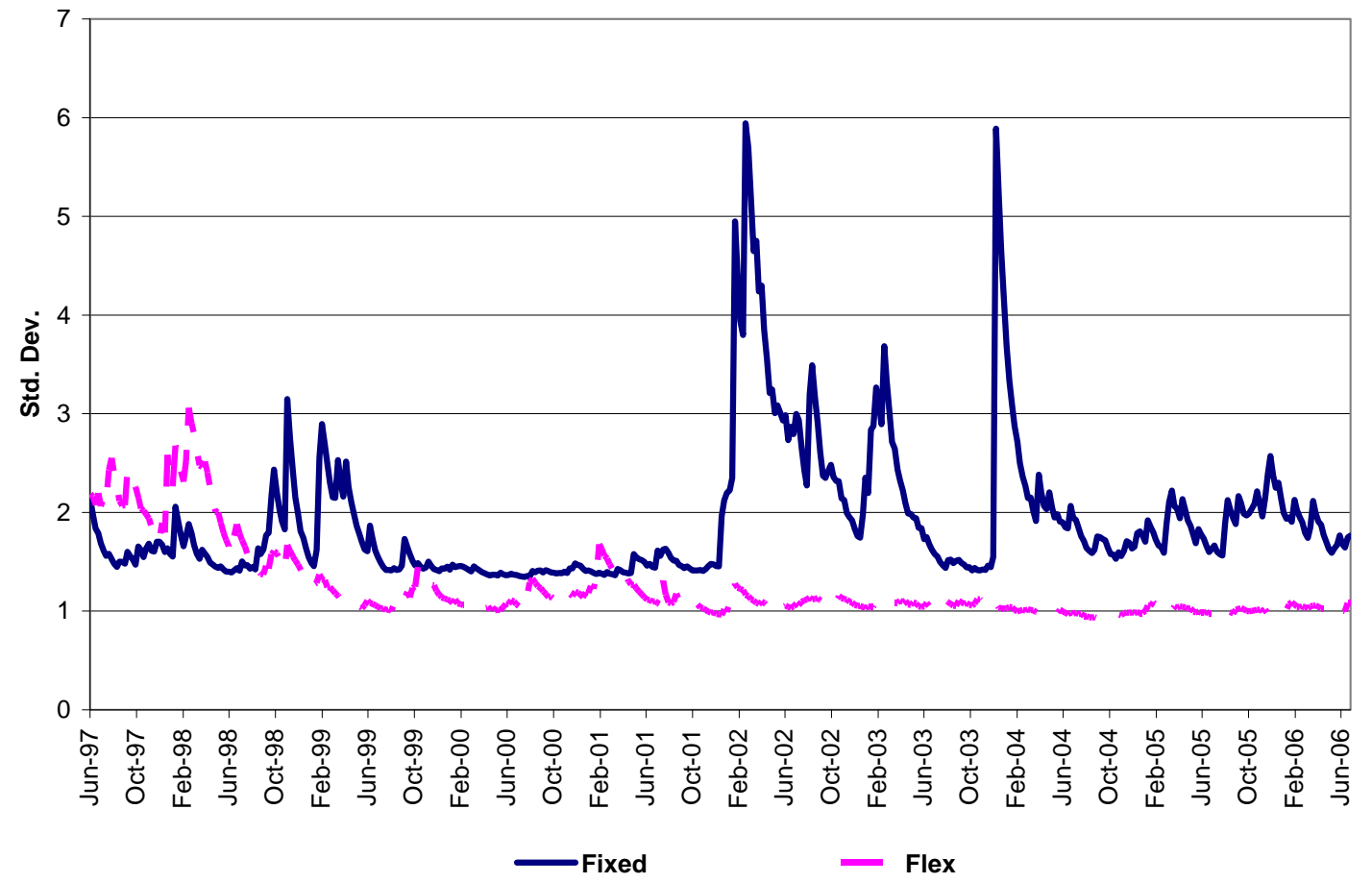

(b) Average Conditional Standard Deviation of Idiosyncratic Interest Rate Factors

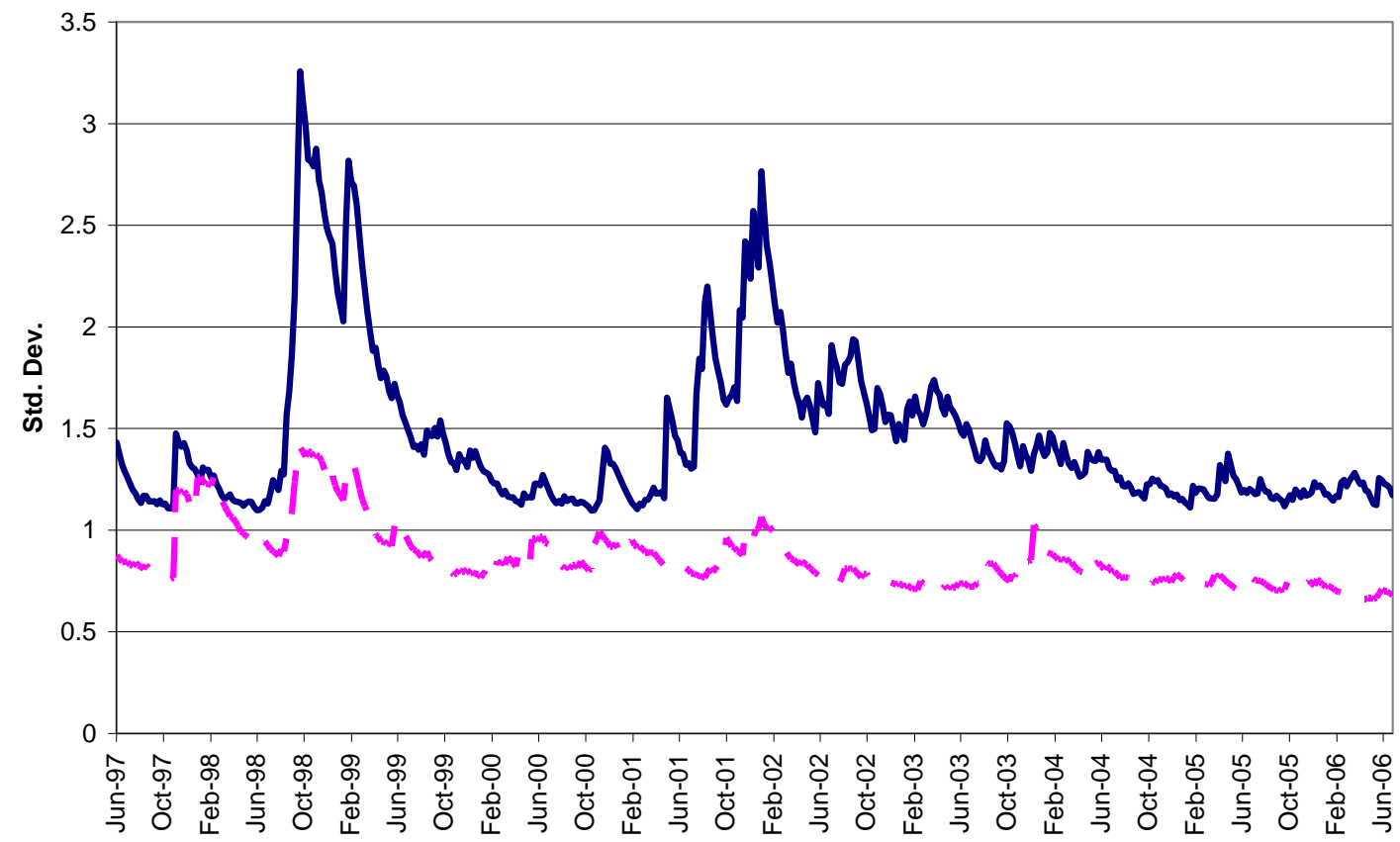

-Fixed $\quad$ Flex 
Figure 2

(a) Net Effect of Idiosyncratic Exchange Rate Volatility on Currency Returns

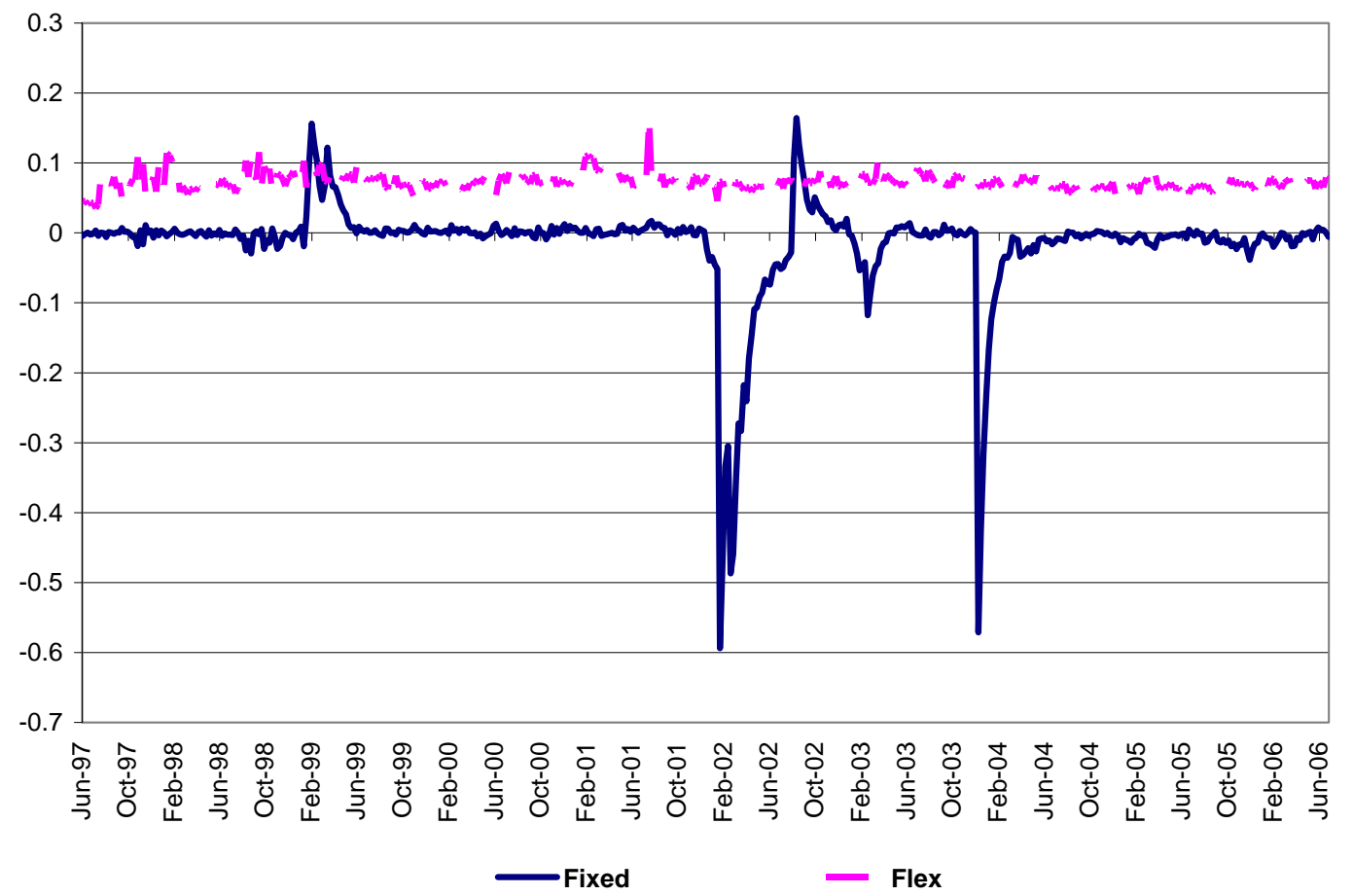

(b) Net Effect of Idiosyncratic Exchange Rate and Interest Rate Volatility on Bond Returns

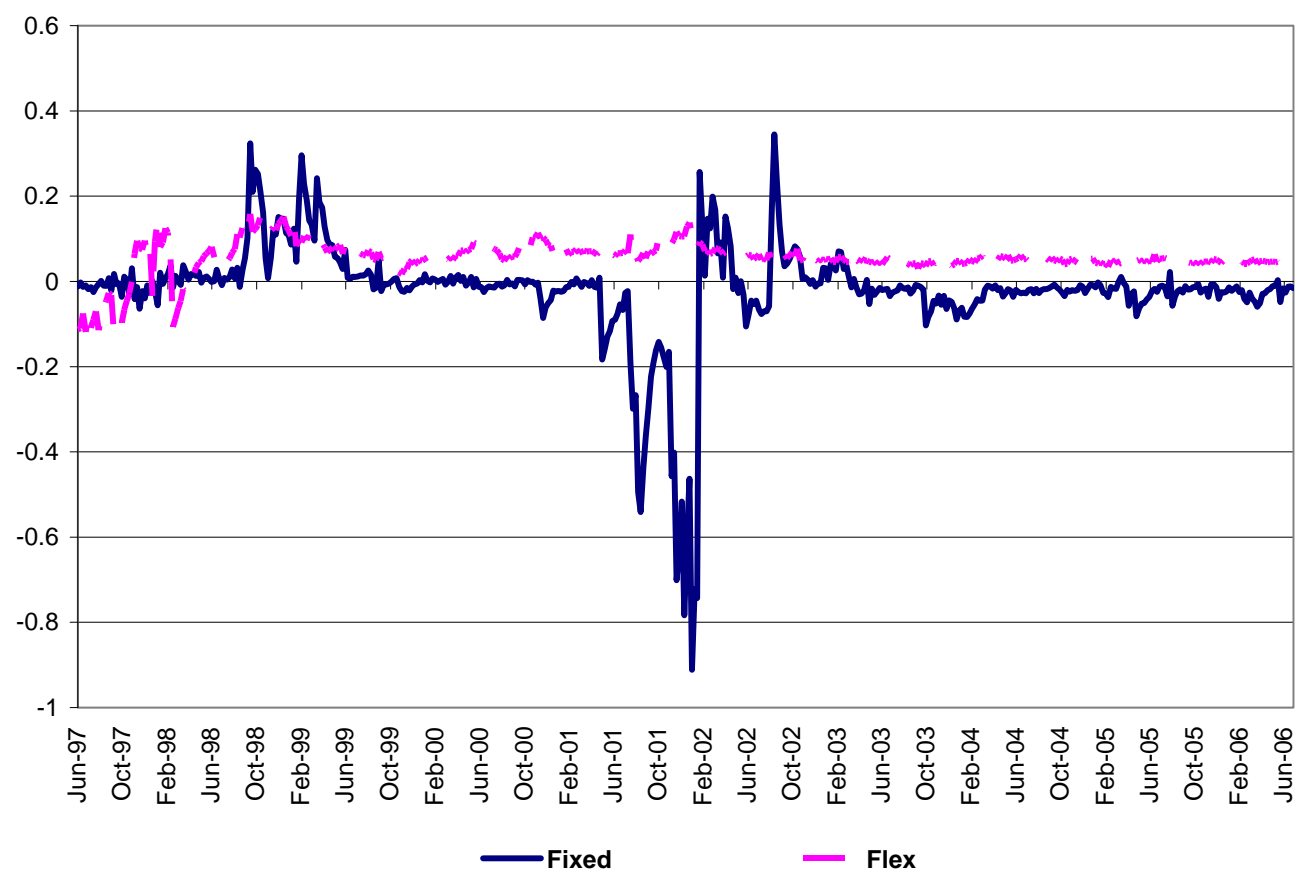


(c) Net Effect of Idiosyncratic Exchange Rate and Interest Rate Volatility on Stock Returns

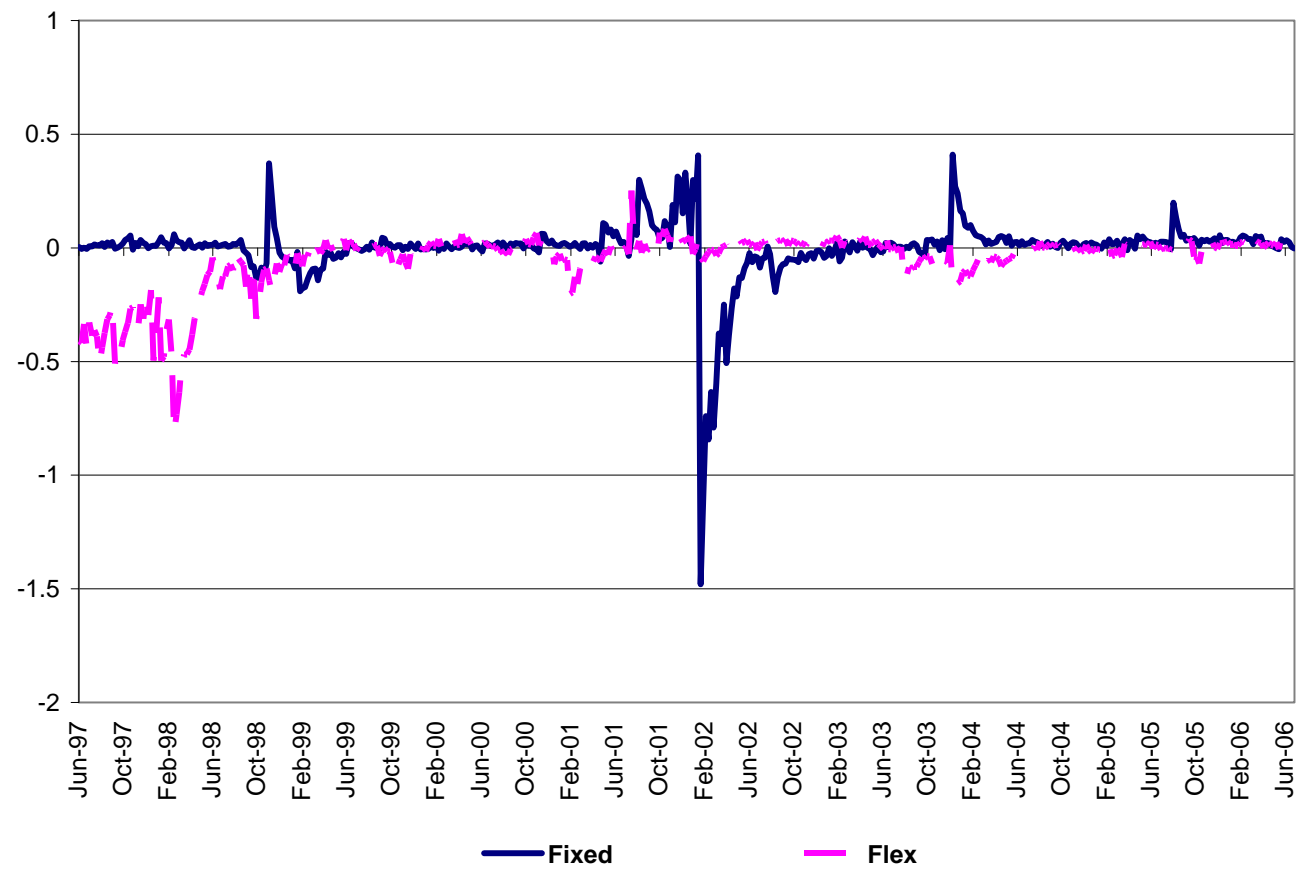

